\title{
Design of an Innovative Furniture System: Improving Acoustic Comfort in Coworking Workplaces
}

\author{
Viola Geniola ${ }^{1, *}$, Stefania Camplone ${ }^{1}$, Antonio Marano ${ }^{1}$ and Emilio Rossi ${ }^{2}$ \\ ${ }^{1}$ Department of Architecture, University of Chieti-Pescara, Viale Pindaro 42, 65127 Pescara \\ (PE), Italy \\ viola.gen1993@gmail.com, \{stefania.camplone, a.marano\}@unich.it \\ ${ }^{2}$ Lincoln School of Design, University of Lincoln, Brayford Pool, Lincoln, LN6 7TS, UK \\ erossi@lincoln.ac.uk
}

\begin{abstract}
Coworking workplaces are shared production areas where the emerging class of 'Millennials' can work together. Unlike traditional 'work-at-home', this new business model shows clear pros for what concerns design-driven innovation, sustainable economies and creative industries. However, noise control and noise-related aspects need to be taken into account since they significantly affect the productivity and the livability of the work environment. To overcome this trend, we propose an innovative furniture system with integrated acoustic insulation panels that meets the new demands for original solutions for creative workplaces, mitigating the noise-related bad effects on workers.
\end{abstract}

Keywords: Design process $\cdot$ Coworking $\cdot$ Innovative furniture system $\cdot$ Acoustic comfort $\cdot$ Smart material

\section{Introduction}

Since 2000's the so-called 'rise of creative class', as described by Richard Florida [1], significantly changed the way workers perform their job and, consequently, the way workplaces have to be designed to meet the new needs creative workers. While 'Millennials' become the archetype of the emerging class of creative workers, which do their businesses in new informal ways, coworking workplaces become the new production areas where they operate, produce new know-how and meet each other.

Coworking workplaces can be defined as shared production areas, often placed in open spaces, where creative companies, makers, start-ups, designers, writers, artists, etc. promiscuously work together. Unlike 'work-at-home' business model, coworking is a collaborative, flexible and voluntary work style based on mutual trust and on the sharing of common core values between participants.

Beyond intrinsic business model's pros, which is one of the most promising design-driven research fields for sustainable economies and creative industries [2], coworking workplaces show a number of critical factors that could affect the quality of work environment. Among these aspects, noise is one the most critical one to take into account [3]. Today, the noise control in workplaces is mainly operated using foam-made insulation panels placed, for example, on walls, ceilings and desks. 
Acoustic insulation panels are essentially produced following performanceoriented criteria, relegating the 'innovation factor' only in the search for better isolation performances. Considering coworking's characteristics, current acoustic insulation panels could be inadequate to meet the end-users' creative-centric and flexibilitydriven needs [4]. New solutions can be developed using rigorous design processes to improve workplaces' noise comfort and to conceive cutting-edge furniture systems.

This paper presents a research developed at the University of Chieti-Pescara in Italy as a part of a M.Sc. Thesis in Architecture focused on the theme of office furniture design [5]. Part of this study has been developed in collaboration with an Italian firm - Metalway S.r.1. - operating in office furniture design since 2000, and on the production of acoustic control panels since 2016. The results obtained demonstrated that the use of a design-driven innovation approach improves both the development of new products and the search of promising market niche for future innovations.

\section{$2 \quad$ Aims}

While coworking areas have inherited traditional office furniture solutions that do not meet Millennials' smart working requirements (i.e. flexibility, nomadism, networking, etc.), this research focused on the design of a new furniture system, specifically conceived to ensure the satisfaction of coworkers' flexibility-related needs, with a particular attention on the mitigation of acoustic noise. In particular, the research aimed to:

- Explore new design-driven prospects and meta-design insights for the innovation in coworking workplaces, beyond the design of 'classic' furnishings.

- Design of a new furniture system to improve the acoustic comfort in coworking workplaces, using focused design guidelines, technical integrations and 'smart materials'.

\section{Methodology}

This study followed a three phase 'Design Process Methodology' combining conventional Design Research approach and focused meetings with the company's managers:

1. Internal audit to investigate acoustic features in coworking workplaces and to find the most promising topics for later design developments.

2. Analysis of end-users interactions in coworking workplaces.

3. Integration between acoustic factors and concept design of new furnishing systems with sound-absorbing panels.

\subsection{Audit-Based Investigation of Acoustic Features in Coworking Workplaces}

The internal audit with the company's managers, made using interviews, observations, data analyses and evaluations, defined the main elements on which to develop the Design Brief. The audit addressed the main topic of the research: the design of 'acoustically performing furniture systems for co-working workplaces'.

The focus on acoustic comfort, besides the chance of improving the company's know how in noise control, is deeply linked to the will to invest in coworking work- 
places, since the current market evidences have shown that in the near future, there will be an increasing in the flexibility of intellectual jobs; thus, coworking connects people from different backgrounds and allow them sharing knowledge, resources, but at the same time, production spaces in order to build business-driven communities and stakeholders' networks. The existence of informal shared areas is crucial to catalyze the workers' interaction, but also it increases noise discomfort: while $86 \%$ of workers appreciate interaction with other people, $70 \%$ of them affirm that they would be more productive in a less noisy work environment [6]. The relevance of sound discomfort is underlined by World Health Organization's (WHO) studies about the impact of noise on health and work-related diseases [7]: workplaces whose sound intensity level is about $60 \mathrm{~dB}$ generate annoyance, which stands for stress, dissatisfaction and concentration problems. This disease is caused also by sound reverberation, which is the acoustic phenomenon affecting large-scale environments such as open spaces, where co-working usually operate. The research outlined the sound comfort as one of the most important human needs to be converted into specific design requirements; later, a preliminary study focused on acoustics comfort was performed to understand what sound-related variables the next design phase should have to be taken into account.

Referring to the activities mainly characterizing coworking, it is possible to classify the production areas in three categories: a) in-between areas, b) relax areas and c) working areas. For each one, detailed information about sound sources, intensity levels and frequency were pointed out. The classification showed that voice is the most disturbing factor since its frequency ranges between $0.17 \mathrm{kHz}$ and $4 \mathrm{kHz}$, which overlaps with the maximum human hearing sensitivity's range: from $2 \mathrm{kHz}$ to $5 \mathrm{kHz}$ [8]. Thus, informal workplace conversations and murmurs are constant and increase the background noise, generating annoyance feelings.

\subsection{Coworkers Analysis}

By definition coworkers have different characteristics, including: age, job, skills, lifestyle, social and cultural attitudes. An overall coworkers' picture can be made using the 'age criteria'; referring to people born from 1945 to 2010, there are: a) baby boomers, b) X and Y generations and c) Millennials. Each generation has been linked to work skills and kind of job to identify main coworkers' profiles as: a) independent contractors and advisors, b) freelancers and c) digital creative professionals - as digital nomads and team workers.

While all coworkers want and benefit to belong to a community, they express different job-related flexibility and privacy's needs. Startupers, for example, aim to work together in informal ways, on the other hand researchers need concentration while writing an article and want soft conversation with other colleagues only when they decide to have a break. Accordingly, the research challenge was to allow the coexistence, in the same environment, of several work-related performances without affecting the end-users' productivity and wellbeing.

The way in which space enhances the relationships between people and work equipment is shown in Fig. 1; it also shows the compatibility/incompatibility of activities through visual and sound permeability. This model has been also used to developed a new one based on flexibility and privacy modulation, which later was used to implement the design requirements. 


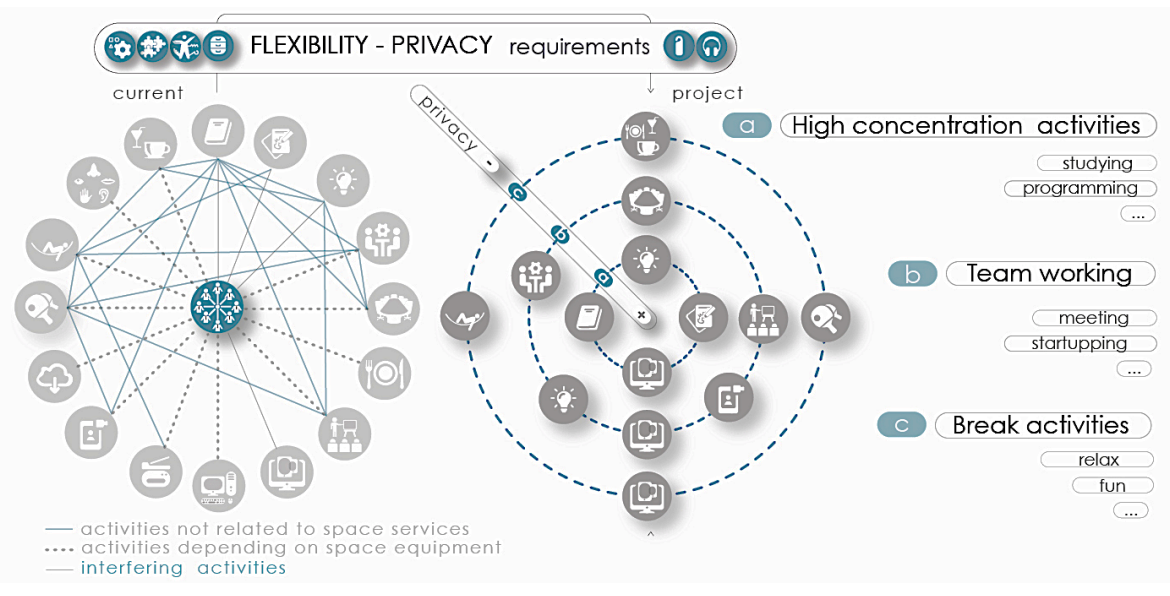

Fig. 1. Correlation between people, work activities, work equipment and space [5].

\subsection{Design Concept of a Furniture System with Sound-Absorbing Elements}

Once established the importance of the acoustic factors, the research examined the their connectability with furnishing: stand-alone superstructure, additional soundabsorbing elements to existing furniture and, finally, integrations with new furniture systems. Considering that every surface existing in coworking spaces influence the sound performance - according to materials - smooth and reflective ones increase reverberation, porous and sound-absorbing ones limit it, then the last option is the most coherent with the design brief.

The conversion of acoustic factors into design requirements was based on the analysis of how acoustic requirement and sound-absorbing coworkers' needs change work equipment. The design concept idea for an innovative furniture system that mitigates the noise in coworking workplaces is composed by a family of different elements, which can be equipped and later freely combined together in order to ensure different space layout and uses by coworkers.

The concept design (Fig. 2) is inspired on one of the fundamental characters defined by coworkers: flexibility. This is morphologically represented as a surface, belonging to each furnishing component, which can change its shape depending on the context where it will be placed and, mostly, the coworkers' needs. Accordingly, all sub-products composing the furniture system, give the chance to multiply the possibilities of use: from office and relax pods elements to the desking system.

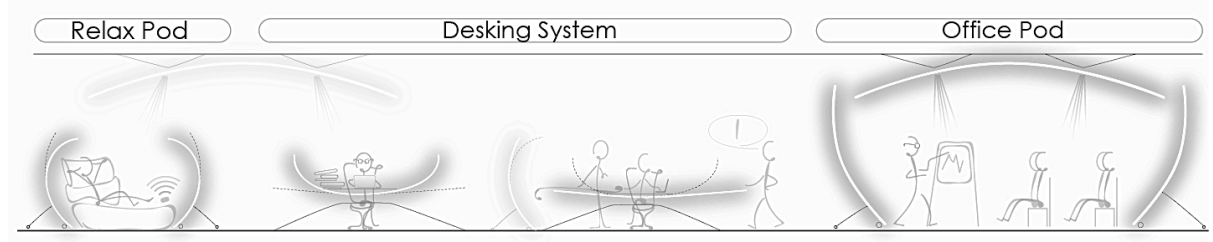

Fig. 2. Furniture system with flexible sound-absorbing elements: Concept design [5]. 


\section{$4 \quad$ Results}

The result of the research was the design of an innovative furniture system. While three elements were initially conceived - a) relax pod, b) desking system, c) office pod - the final experimentation focused only on the design of the desking system.

The innovation introduced was not only related on the development of an innovative set of solutions, but also on the use on new materials, which expanded the design possibility in the shaping of more organic solutions, meeting then the phenomenological propagation of sound waves. In particular, the use of 'Clash' [9], a new shape memory alloy (SMA), introduced the formal changeability of solutions. Clash is a multilayered structure made in soft \& hard polyurethane and containing a SMA sandwich made of a copper foil and titanium/nickel wires. The inner layer, when heated, produces a change in the material shape and, when cooled, it preserves the shape before impressed. Clash has acoustically performing outer layers made in polyurethane, which is a sound-absorbing polymeric material with open cells. Clash fits bots the main requirements contained in the design brief - sound absorption through porosity of polyurethane material - and also the flexibility, by its shape-changing ability.

The desking system (Fig. 3) is a personal workstation that can be configured by two privacy levels. The desk is formed by two layered surfaces: the upper surface, closer to the end-users, is a flat and hard surface equipped with wireless recharging connectors; the lower surface, instead, is made of Clash and can be curved upwards or be flatted. In the first case, end-users are shielded from the surrounding space, for example when they are more prone to concentration or to individual work activities; when the surface is flatted, the visual contact with other coworkers is maximum, so people can relate and co-work. While the upper desk is almost organically shaped, the Clash-made surface has regular edges, which are functional to make easier the desks joining - this aspect creates a clear distinction between private areas and shared ones where end-users can connect themselves, work equipment and ideas.

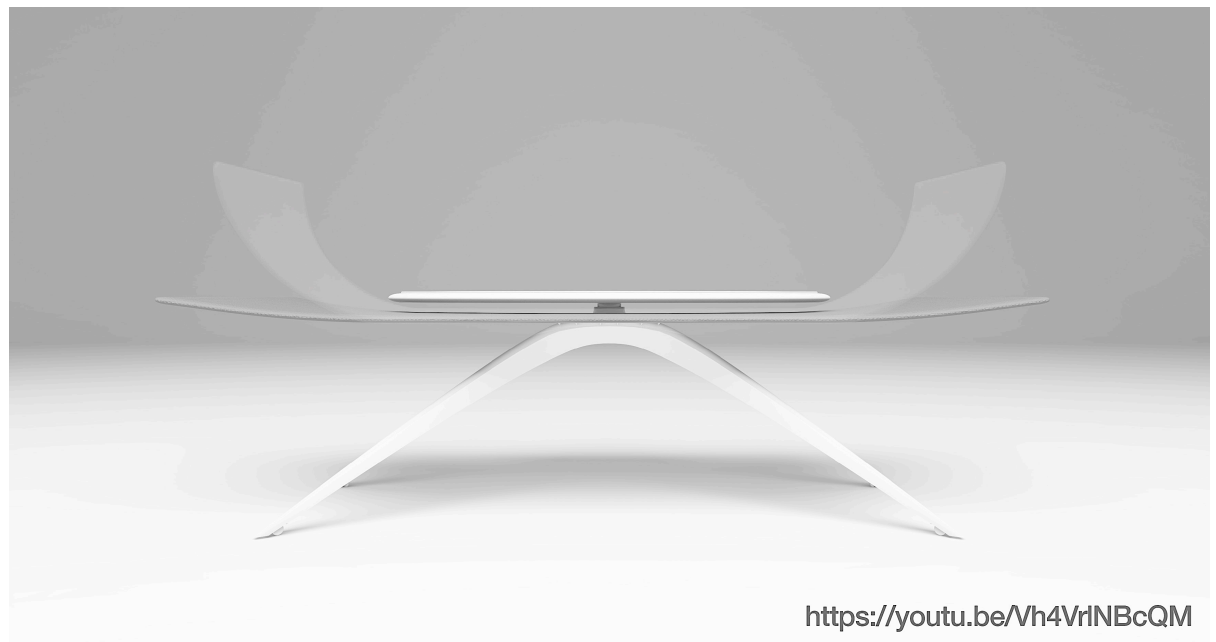

Fig. 3. Desking system with movable Clash-made sound-absorbing surfaces [5]. 


\section{Conclusions}

Since companies' organizational structure has changed towards flexibility and decentralization, end-users' needs are no longer tied to a single workplace or to a 'static' furniture; mobility and nomadism, time and place flexibility have influenced the working activities toward new 'smart' meanings connecting people, skills, communities and networks. In this transition, coworking has become one of the most promising business models influencing the design of work environments and, consequently, the design of furniture to be used by Millennials, which have new needs less tied to a standardized vision of work.

The preliminary design concept achieved using a rigorous design process and the later design development of a desking system with movable Clash-made soundabsorbing surfaces, demonstrated that it is possible to produce significant innovations in furniture design for coworking workplaces; this design-driven innovation is not due only to the fact the project meets specific end-users' need, but it is also related to the chance of have a set of products that, by combination, can generate multiple - 'smart' - configurations to enable new generations of workers in facing complex tasks.

The coherence with the research results, based on clear research goals, proves the relevant role of Design discipline in new product development process, which is strategic to increase manufacturers' innovativeness, competitiveness and quality.

\section{Credits}

This paper shows the research results achieved in a M.Sc. thesis in Architecture developed at the University of Chieti-Pescara in Italy by Viola Geniola [5]. The formal writing of paragraphs is attributed to: Viola Geniola for 'Methodology', Stefania Camplone for 'Results', Antonio Marano for 'Abstract' and 'Introduction', and finally to Emilio Rossi for 'Aims' and 'Conclusions'. Authors would also like to thank Metalway S.r.l.'s managers for their invaluable support throughout the research.

\section{References}

1. Florida, R.: The Rise of the Creative Class: And How It's Transforming Work, Leisure and Everyday Life. Basic Books, New York (2002)

2. Boyd, S.: Beyond The Office: Workplace As A Service. (2014) Retrieved from: https://medium.com/stowe-boyd/beyond-the-office-workplace-as-a-service-e70c94f84c69

3. Simonelli, G., Scullica, F., Elgani, E. \& Monna, V.: Can Coworking Spaces be Built Bottom-Up? In: Proceedings of ServDes.2018 Conference, Milan, Italy. pp. $761-771$ (2018)

4. Duffy, F.: The New Office. Conran Octopus Limited, London (1997)

5. Geniola, V.: Design Process per un Sistema di Coworking ad Alto Comfort Acustico. M.Sc. Dissertation, University of Chieti-Pescara, (2019)

6. American Society of Interior Designers, http://asid.org/

7. World Health Organization: Environmental Noise Guidelines for the European Region (2018). World Health Organization, Geneva (2018)

8. Spagnolo, R.: Manuale di Acustica Applicata. Città Studi Edizioni, Turin (2005)

9. Tecnologie e Materiali per il Design, https://tecmatied.wordpress.com/ 